\title{
Is there a demand for physical activity interventions provided by the health care sector? Findings from a population survey
}

\author{
Matti E Leijon ${ }^{1,2^{*}}$, Diana Stark-Ekman², Per Nilsen ${ }^{2}$, Kerstin Ekberg ${ }^{3}$, Lars Walter ${ }^{4}$, Agneta Ståhle ${ }^{5}$, Preben Bendtsen ${ }^{2}$
}

\begin{abstract}
Background: Health care providers in many countries have delivered interventions to improve physical activity levels among their patients. Thus far, less is known about the population's interest to increase their physical activity levels and their opinion about the health care provider's role in physical activity promotion. The aims of this paper were to investigate the self-reported physical activity levels of the population and intention to increase physical activity levels, self-perceived need for support, and opinions about the responsibilities of both individuals and health care providers to promote physical activity.

Methods: A regional public health survey was mailed to 13440 adults (aged 18-84 years) living in Östergötland County (Sweden) in 2006. The survey was part of the regular effort by the regional Health Authorities.

Results: About $25 \%$ of the population was categorised as physically active, $38 \%$ as moderately active, $27 \%$ as somewhat active, and $11 \%$ as low active. More than one-third (37\%) had no intentions to increase their physical activity levels, $36 \%$ had thought about change, while $27 \%$ were determined to change. Lower intention to change was mainly associated with increased age and lower education levels. $28 \%$ answered that physical activity was the most important health-related behaviour to change "right now" and 15\% of those answered that they wanted or needed support to make this change. Of respondents who might be assumed to be in greatest need of increased activity (i.e. respondents reporting poor general health, BMI>30, and inactivity) more than one-quarter wanted support to make improvements to their health. About half of the respondents who wanted support to increase their physical activity levels listed health care providers as a primary source for support.
\end{abstract}

Conclusions: These findings suggest that there is considerable need for physical activity interventions in this population. Adults feel great responsibility for their own physical activity levels, but also attribute responsibility for promoting increased physical activity to health care practitioners.

\section{Background}

Health-related behaviours such as physical activity, diet, alcohol use and smoking, contribute substantially to adult health status $[1,2]$. Numerous approaches have been taken at national and regional levels to influence adults to change their health-related behaviours in order to improve their health and quality of life. In recent years primary health care (PHC) providers have delivered interventions to improve physical activity levels among patients in many countries, including Sweden

\footnotetext{
* Correspondence: mattilleijon@med.lu.se
${ }^{1}$ Center for Primary Health Care Research, Lund University/Region Skåne,

* Correspondence: matti.leijon@med.lu.se
${ }^{1}$ Center for Primary Health Care Research, Lund University/Region Skåne, Malmö, Sweden
}

(c) 2010 Leijon et al; licensee BioMed Central Ltd. This is an Open Access article distributed under the terms of the Creative Commons

[3-9]. These interventions are often referred to as exercise prescriptions or physical activity referral (PAR) schemes $[3,5,6,8]$. Many of these interventions include brief face-to-face communication about the importance of physical activity along with written prescriptions for physical activity. These methods and interventions differ in content in different settings, but are generally regarded as acceptable and feasible, both to practitioners and patients $[8,10]$. Still, there is limited evidence, especially about the long term effect of these interventions $[3,11,12]$. In addition, little is known about which part of the population gains the most benefit from physical activity interventions [3] and about the patients' 
opinions about the role of health care providers in physical activity promotion.

This paper presents data from a regional public health survey conducted amongst adults living in Östergötland County in Sweden. The main purposes were to investigate the populations' self-reported 1) physical activity levels; 2) intentions to change their physical activity levels; 3) need for support; and 4) opinions on the responsibilities of both the individual and health care providers to promote physical activity in the adult population.

\section{Methods}

A population survey was conducted in March 2006, as part of a regular effort by Health Authorities in Östergötland County, southern Sweden, to monitor health and the prevalence of risk factors in the general adult population. This county (population 416,000 ) is the fourth largest in Sweden with two large cities $(>120,000$ inhabitants combined) and 11 smaller, more rural municipalities. The survey's target population were county residents aged 18-84 years ( $\mathrm{n}=315587)$. A questionnaire, consisting of 20 pages, was mailed to a sample of 13440 individuals. Two reminders and an extra survey were sent to non-responders. The sample was stratified by gender, age, and municipalities resulting in 104 strata, with simple random sampling within each stratum [13]. The questionnaire and the survey were designed by the County Council's Public Health Department. The sample was administered by Statistics Sweden. A summary of the questions and the response items are presented in additional file 1. Ethical approval was not required, as data collection was part of the health care routine system.

The survey included a series of questions on healthrelated behaviour including questions about nutrition, physical activity, alcohol consumption, tobacco use and weight [14]. Physical activity was assessed by two questions (see additional file 1), one on physical activity in everyday life and one on exercise during the last 12 months. Responses from the two questions were categorised using a four-level physical activity index: low active, somewhat active, moderately active and physically active according to, or close to, public health recommendations level, normally set as 30 minutes of moderately intensive activity at least 5 days a week or 150 minutes a week or a more vigorously intensive activity at least 75 minutes a week [15-18]. The purpose of these measures is not primarily to provide precise estimates of the activity level, but more to differentiate between those who are more or less active.

Participants were asked if they had considered changing any health-related behaviour, which health risk behaviour they considered to be the most important to change "right now", and if they wanted or needed support to make these changes. If respondents wanted or needed support, they were asked to identify which support systems or care providers that would be most helpful in effecting change, including PHC, hospital, occupational health service, dentist, pharmacy, Internet, and a free text fill-in response alternative. Respondents were also asked questions regarding their opinions about personal responsibility for conducting a physically active lifestyle, and their opinions concerning health care providers' responsibilities in promoting physically active lifestyles (see additional file 1).

We combined many survey responses into larger categories. For example, responses measuring "support sources for change" were recombined into a dichotomous variable, consisting of "Health care" and "Others". The definition of "Health care" consisted of primary health care, hospital, occupational health service, and pharmacy; the "Others" category consisted of two responses: Internet and free text options not related to the health care service. Items asking respondents to agree with statements regarding responsibility for promoting physical activity in the adult populations included the following response alternatives: very much, somewhat, not much, very little. These alternatives are presented as a dichotomous variable; "Great" (including those who responded very much and somewhat) and "Little" (including those responding not much and very little). The self-reported economy question (a proxy for income or socio-economic position) included five response alternatives including "Neither good nor poor". The options "Very good" and "Rather good" are presented as "Good". "Very poor" and "Rather poor" are presented as "Poor". To measure general health status, we used one fill-in-the-blank question: "In general, would you say your health is?" Responses were dichotomised as: "Good" (comprised of those responding with "Excellent", "Very good" and "good") or "Poor" (response alternatives "Fair" and "Poor").

The overall response rate of the survey was $54 \%$ ( $n=$ 7238). More females (59\%) than males (49\%) responded to the survey. The highest response rate $(69 \%)$ was from respondents in the oldest age group (65-84 years). The youngest age group (18-29 years) had the lowest response rate $(40 \%)$.

All statistical analyses were adjusted for survey design and non-responses [19]. The final weights that were used in the analyses were calibrated at Statistics Sweden according to respondents' country of birth, civil status, level of education and occupation. To determine categorical differences between groups (i.e. sexes, age groups etc.), Pearson's chi-squared test was used. A $p$-value below 0.05 was regarded as significant. All statistical analyses were performed by SPSS version 15.0. 


\section{Results}

About 25\% of the adult population in Östergötland was categorised as physically active (Table 1). Higher activity levels were associated with younger age groups, higher education levels, higher income levels, better selfreported general health status, and lower body mass index (BMI).

Intentions to change varied among respondents. Table 2 shows that $37 \%$ of the respondents had no intention of changing their physical activity level, 36\% had thought about change, but "not just now", and 27\% were determined to change "right now". Lower intention to change was mainly associated with increased age and lower education levels.

Respondents ranked health-related behaviours they considered to be most important to change "right now". Physical activity was the leading item on this list, with $28 \%$ of all participants choosing this item. There were however differences between the groups; with results ranging from $12 \%$ up to $41 \%$ (see Table 3 ). Moreover, $24 \%$ considered "Lose weight" to be the most important health behaviour change "right now", 16\% answered "Healthier eating", 5\% "Quit smoking”, 2\% "Lowering alcohol consumption" and 1\% "Quit taking snuff". "Tobacco use", presented here as smoking and use of snuff, was considered to be the most important healthrelated behaviour to change by $33 \%$ of the smokers, and by $9 \%$ of the snuff users.

Among those ranking physical activity as the most important behaviour to change, $15 \%$ answered that they wanted or needed support to make this change (see Table 3). Factors associated with wanting or needing support included female sex, lower physical activity, obesity, poor health, and lower self-reported income levels. Half of the respondents, when identifying primary sources of support for change, listed assorted health care providers. The highest percentage listed support from PHC providers as the primary source of support for change. These responses were associated with older age (especially females) and those describing themselves as inactive.

Almost all (97\%) participants agreed that it is the individual's own responsibility to ensure a sufficient physical activity level. However, three out of four (76\%) also thought that health care providers had a great responsibility to promote physical activity levels among patients.

Table 1 Physical activity levels in the adult population (18-84) years of Östergötland in 2006

\begin{tabular}{|c|c|c|c|c|c|c|}
\hline & & & Phy & ical activity level & & \\
\hline & $n$ & $\begin{array}{c}\text { Low active } \\
(\%)\end{array}$ & Somewhat active (\%) & Moderately active (\%) & Physically active (\%) & $p$-value \\
\hline$\overline{\text { Total }}$ & 6966 & 11 & 27 & 38 & 25 & \\
\hline Sex & & & & & & $<0.01$ \\
\hline Females & 3802 & 10 & 25 & 40 & 24 & \\
\hline Males & 3164 & 11 & 29 & 35 & 25 & \\
\hline Age groups (years) & & & & & & $<0.01$ \\
\hline $18-29$ & 1294 & 9 & 16 & 34 & 41 & \\
\hline $30-44$ & 1589 & 10 & 27 & 36 & 27 & \\
\hline $45-64$ & 1948 & 10 & 31 & 39 & 21 & \\
\hline $65-84$ & 2135 & 14 & 33 & 40 & 12 & \\
\hline Education & & & & & & $<0.01$ \\
\hline Compulsory school & 2059 & 16 & 34 & 38 & 13 & \\
\hline Upper secondary school & 3293 & 10 & 26 & 37 & 27 & \\
\hline Post-secondary school & 1446 & 6 & 21 & 38 & 35 & \\
\hline Self-reported economy & & & & & & $<0.01$ \\
\hline Good & 3865 & 9 & 26 & 39 & 27 & \\
\hline Neither good nor poor & 2042 & 12 & 28 & 36 & 24 & \\
\hline Poor & 908 & 15 & 30 & 36 & 19 & \\
\hline General health & & & & & & $<0.01$ \\
\hline Good & 5456 & 8 & 24 & 39 & 29 & \\
\hline Poor & 1456 & 20 & 36 & 33 & 11 & \\
\hline Body mass index $(\mathrm{BMI})\left(\mathrm{kg} / \mathrm{m}^{2}\right)$ & & & & & & $<0.01$ \\
\hline$<25$ & 3400 & 8 & 22 & 38 & 32 & \\
\hline $25.0-29.9$ & 2373 & 11 & 32 & 38 & 20 & \\
\hline$>30$ & 877 & 20 & 36 & 33 & 11 & \\
\hline
\end{tabular}


Table 2 Intention to change physical activity level in the adult population (18-84 years) of Östergötland in 2006

\begin{tabular}{|c|c|c|c|c|c|}
\hline & & $\mathrm{Hav}$ & you considered increasing your phy & activity? & \\
\hline & $\mathrm{n}$ & $\begin{array}{c}\text { "No, I have no intention to } \\
\text { change" (\%) }\end{array}$ & $\begin{array}{c}\text { "Yes, I have thought about change } \\
\text { but not just now" (\%) }\end{array}$ & $\begin{array}{l}\text { "Yes, I am determined to } \\
\text { change right now" (\%) }\end{array}$ & $\begin{array}{c}\mathrm{p}- \\
\text { value }\end{array}$ \\
\hline Total & 6569 & 37 & 36 & 27 & \\
\hline Sex & & & & & $<0.01$ \\
\hline Females & 3552 & 35 & 36 & 29 & \\
\hline Males & 3017 & 39 & 37 & 24 & \\
\hline Age groups (years) & & & & & $<0.01$ \\
\hline $18-29$ & 1289 & 24 & 38 & 38 & \\
\hline $30-44$ & 1580 & 24 & 41 & 34 & \\
\hline $45-64$ & 1883 & 41 & 37 & 21 & \\
\hline $65-84$ & 1817 & 64 & 25 & 11 & \\
\hline Education & & & & & $<0.01$ \\
\hline $\begin{array}{l}\text { Compulsory } \\
\text { school }\end{array}$ & 1782 & 50 & 33 & 17 & \\
\hline $\begin{array}{l}\text { Upper secondary } \\
\text { school }\end{array}$ & 3215 & 34 & 38 & 29 & \\
\hline $\begin{array}{l}\text { Post-secondary } \\
\text { school }\end{array}$ & 1422 & 32 & 37 & 31 & \\
\hline $\begin{array}{l}\text { Self-reported } \\
\text { economy }\end{array}$ & & & & & $<0.01$ \\
\hline Good & 3667 & 40 & 34 & 26 & \\
\hline $\begin{array}{l}\text { Neither good nor } \\
\text { poor }\end{array}$ & 1908 & 36 & 39 & 25 & \\
\hline Poor & 861 & 30 & 40 & 31 & \\
\hline General health & & & & & $<0.01$ \\
\hline Good & 5243 & 36 & 36 & 28 & \\
\hline Poor & 1284 & 40 & 40 & 21 & \\
\hline $\begin{array}{l}\text { Body mass index } \\
(\mathrm{BMI})\left(\mathrm{kg} / \mathrm{m}^{2}\right)\end{array}$ & & & & & $<0.01$ \\
\hline$<25$ & 3270 & 42 & 34 & 24 & \\
\hline $25-29.9$ & 2229 & 34 & 38 & 28 & \\
\hline$>30$ & 796 & 23 & 44 & 33 & \\
\hline Activity level & & & & & $<0.01$ \\
\hline Low active & 625 & 27 & 54 & 19 & \\
\hline Somewhat active & 1699 & 26 & 47 & 27 & \\
\hline Moderately active & 2530 & 39 & 34 & 27 & \\
\hline Physically active & 1543 & 49 & 22 & 29 & \\
\hline
\end{tabular}

Such responses were associated with higher education levels, higher income levels, better general health, and higher activity levels amongst respondents. About half of respondents (47\%) also thought that health care providers had high responsibility to promote physical activity in the general population. Factors associated with agreement on this statement included older age, higher income levels, and poor general health.

\section{Discussion}

The present study is one of only a few Swedish large scale population surveys on lifestyle related issues. We found that one-quarter of the population was categorised as physically active. This is consistent with findings from two previous studies that include Swedish populations: the Eurobarometer study from 2002, and a population survey in the same region as in the present study from 1999 . Both studies report that $23 \%$ of the respondents were categorised as physically active $[20,21]$.

Results from the survey's question about intention to change the level of physical activity showed that approximately one third of the population had no intention to change; one third had thought about change and one third were determined to change their physical activity level. This distribution gives a good overview about the willingness to change the level of physical activity in the population. Information about differences 
Table 3 Priorities in the adult population (18-84 years) regarding the need to increase physical activity levels, the need for external support to increase physical activity levels, and the anticipated venues for this support

\begin{tabular}{|c|c|c|c|c|c|c|c|c|c|c|}
\hline & & st important to $\mathrm{cl}$ & nge & & Support to chan & & & Suppo & etting & \\
\hline & $\mathrm{n}$ & $\begin{array}{l}\text { Physical activity } \\
(\%)\end{array}$ & $\begin{array}{c}\mathrm{p}- \\
\text { value }\end{array}$ & $\mathrm{n}$ & $\begin{array}{l}\text { Want support } \\
(\%)\end{array}$ & $\begin{array}{c}\mathrm{p}- \\
\text { value }\end{array}$ & $\mathrm{n}$ & $\begin{array}{l}\text { Health care* } \\
(\%)\end{array}$ & $\begin{array}{l}\text { Other** } \\
(\%)\end{array}$ & $\begin{array}{c}\mathrm{p}- \\
\text { value }\end{array}$ \\
\hline Total & 6862 & 28 & & 1727 & 15 & & 244 & 50 & 50 & \\
\hline Sex & & & $<0.01$ & & & $<0.01$ & & & & 0.46 \\
\hline Females & 3743 & 26 & & 925 & 20 & & 154 & 52 & 48 & \\
\hline Males & 3119 & 30 & & 802 & 11 & & 90 & 47 & 53 & \\
\hline Age groups (years) & & & $<0.01$ & & & 0.08 & & & & $<0.01$ \\
\hline $18-29$ & 1285 & 40 & & 476 & 14 & & 63 & 19 & 81 & \\
\hline $30-44$ & 1574 & 38 & & 578 & 13 & & 87 & 47 & 53 & \\
\hline $45-64$ & 1929 & 21 & & 419 & 18 & & 62 & 71 & 29 & \\
\hline $65-84$ & 2074 & 12 & & 254 & 19 & & 32 & 77 & 23 & \\
\hline Education & & & $<0.01$ & & & 0.60 & & & & 0.21 \\
\hline Compulsory school & 2003 & 14 & & 285 & 13 & & 32 & 69 & 31 & \\
\hline Upper secondary school & 3276 & 29 & & 901 & 14 & & 125 & 46 & 54 & \\
\hline Post-secondary school & 1406 & 41 & & 514 & 16 & & 80 & 53 & 48 & \\
\hline Self-reported economy & & & $<0.01$ & & & $<0.01$ & & & & 0.09 \\
\hline Good & 3804 & 29 & & 980 & 13 & & 117 & 59 & 41 & \\
\hline Neither good nor poor & 1998 & 26 & & 472 & 14 & & 71 & 43 & 57 & \\
\hline Poor & 899 & 27 & & 243 & 25 & & 51 & 38 & 62 & \\
\hline General health & & & $<0.01$ & & & $<0.01$ & & & & 0.08 \\
\hline Good & 5381 & 30 & & 1466 & 13 & & 174 & 46 & 54 & \\
\hline Poor & 1429 & 18 & & 253 & 30 & & 70 & 63 & 37 & \\
\hline $\begin{array}{l}\text { Body mass index (BMI) (kg/ } \\
\left.\mathrm{m}^{2}\right)\end{array}$ & & & $<0.01$ & & & $<0.01$ & & & & 0.69 \\
\hline$<25$ & 3298 & 36 & & 1033 & 13 & & 125 & 48 & 52 & \\
\hline $25-29.9$ & 2365 & 24 & & 525 & 15 & & 73 & 51 & 49 & \\
\hline$>30$ & 880 & 15 & & 111 & 27 & & 34 & 58 & 42 & \\
\hline Activity level & & & $<0.01$ & & & $<0.01$ & & & & $<0.01$ \\
\hline Low active & 690 & 31 & & 205 & 23 & & 49 & 64 & 36 & \\
\hline Somewhat active & 1792 & 33 & & 552 & 17 & & 89 & 58 & 42 & \\
\hline Moderately active & 2612 & 26 & & 627 & 14 & & 71 & 47 & 53 & \\
\hline Physically active & 1558 & 24 & & 317 & 10 & & 32 & 20 & 80 & \\
\hline
\end{tabular}

* including; primary health care, hospital, occupational health services and pharmacy

** including Internet and free text options not related to the health care service.

within sub-groups can be very useful when planning physical activity interventions. Thus, we found that two groups had minimal intentions to change their physical activity levels: those in the older age groups and those with lower education levels. This finding indicates that interventions to achieve increased physical activity in these groups require specialised approaches to enhance their motivation.

In the present study, the respondents' current activity levels were related to intention to change, but the results are somewhat ambiguous. Among respondents categorised as physically active, half answered that they had no intention to change, which indicates that they were satisfied with their current activity level. On the other hand, half of those included in the physically active group were thinking about or were determined to change their activity levels. More than half of those categorised as low active had "thought about change but not just now", with about one-fifth determined to make improvements in physical activity levels. These findings indicate that there may be subgroups in each category that are ready to take on additional activity, and that would possibly benefit from support from PHC providers. Identifying other markers that indicate strong readiness to change physical activity levels would help pinpoint which groups should be targeted.

More than one out of four respondents (28\%) considered increased physical activity to be the most important health-related behaviour to change "right now", more important than losing weight, making healthier eating 
selections, quitting tobacco use or reducing alcohol consumption. Among respondents who considered physical activity to be the most important health-related behaviour to change, $15 \%$ also reported that they would welcome active, targeted support to increase their physical activity level. This finding does however not include those identifying other behaviours than physical activity as the most important to change "right now". Thus it may not mirror the opinion of the entire population. Still, the figures give an indication about the desired levels of support requested by different groups in the population. Of respondents who might be assumed to be in greatest need of increased activity (i.e. respondents reporting poor general health, $\mathrm{BMI}>30$, and inactivity) more than one-quarter wanted support to increase their physical activity. This group also, to a larger extent, requested support from health care providers to increase their physical activity level.

Although most respondents stated that they were personally responsible for ensuring that they were physically active, a large majority among all sub-groups also felt that health care providers held responsibility for supporting physical activity both among patients and in the broader population. This finding is in line with a study by Albright et al. that showed that patients not only seek lifestyle advice from their health-care providers, but also anticipate discussions of such issues as part of their medical care [22]. Moreover, a Swedish study by Johansson et al. found that patients who receive support for health behaviour change are more satisfied with their consultation than patients who are not offered this type of information [23].

The results of the current study show that elderly and patients with poor general health, high BMI, and lower activity levels were the groups with the highest selfreported wish or need for support from health care providers. These findings are interesting from a professional to patient as well as from a public health point of view, since it is beyond dispute that it is important to increase physical activity levels in the most inactive groups in society. Even small increases in activity level among sedentary populations have greater potential to influence public health than increased activity levels of those who are already active [24,25]. It is important, both for the individual and the society, to find physical activity interventions that are effective for vulnerable groups that are at high risk of developing health behaviour-related diseases. Many physical activity interventions appear to reach primarily those in good health who are already active [26]. Appropriate interventions targeting disadvantaged groups will serve to reduce health disparities in the population rather than increase them [27].

Our findings indicate that health care-based physical activity interventions are likely to be welcomed by those patients in most need of increased physical activity. Health care providers working in primary health care settings, geographically distributed across the nation, have broad access to the adult population. They are in a natural position to share information about interventions aiming to improve the overall health status within the population, particularly among those with health problems $[28,29]$. In Sweden, approximately $70 \%$ of the population consult a primary health care provider each year [30]. A targeted use of interventions such as PARs can help the least active patients by outlining step-bystep approaches, which takes age, gender, current activity level, activity history, motivation, and health conditions into consideration, ensuring that the physical activity levels are appropriate,

Many different interventions are available to improve physical activity in the general population today and their results have multiple effects when they are combined. Our study focuses on identifying patients who would benefit most from support by health care providers to increase their physical activity levels. Extrapolation of the results of the present study may help to formulate policy recommendations: the study suggests that inactive patients will benefit most from health care support to increase their physical activity levels. Policy recommendations for health care providers may help them to serve as motivators of this less active patient group. Incentives to primary health care centres to allow for extra time during office visits, for example, may be well worth examining.

Our study has a number of limitations that must be considered when interpreting the results. The indices of physical activity level were derived from two questions about activity in daily life and exercise, resulting in a measurement that has not yet been validated. When this survey was planned there was no simple validated physical activity question available in Sweden, thus we used the index items used in a previous population survey. The survey as a whole used simple questions to fulfil the aim to monitor the general health in Östergötland County. Moreover, the overall response rate to this survey was $54 \%$, with considerably lower proportions of respondents in certain groups, lowering the generalisability of the results. The separate questions in the survey allowed for non-response, which resulted in different totals for individual survey items (with responses ranging from 6966-6569). The distribution of the nonrespondents probably also lower the survey's generalisability. For example, there were fewer responses from inactive respondents than from more active respondents to the questions about intention to change. Another weakness of the study is the quite small number of persons in some of the sub-samples (see Table 3), which may make it more difficult to detect statistically 
significant differences between different categories. Still, and despite previous mentioned shortcomings, the large overall number of respondents to the survey is a considerable strength of the study.

\section{Conclusions}

The findings from this study suggest that there is considerable need for physical activity interventions in the general population. Adults feel great responsibility for their own physical activity levels, but also attribute responsibility for promoting increased physical activity to health care practitioners. In our study population, a significant number of low active adults thought about change or were determined to change their physical activity level. Health care providers might wish to target their efforts to this group of patients to achieve the largest public health impact.

Additional file 1: Appendix A \& B. Variables used from the population survey and physical activity index including questions and response items.

Click here for file

[http://www.biomedcentral.com/content/supplementary/1471-2458-1034-S1.DOC]

\section{Acknowledgements}

This survey was created by the County Council's Public Health Department, according to its ordinary commission by the County Councils politicians. We want to thank all colleagues at the Centre for Public Health Sciences in Linköping for all the hard work related to this population survey, especially Helen Axelsson for statistical analyses and Lena Lindhe-Söderlund for the idea of including behaviour change questions in the questionnaire. Funding: County Council of Östergötland

\section{Author details \\ ${ }^{1}$ Center for Primary Health Care Research, Lund University/Region Skåne, Malmö, Sweden. ${ }^{2}$ Department of Medical and Health Sciences, Division of Community Medicine, Social Medicine and Public Health Science, Linköping University, Linköping, Sweden. ${ }^{3}$ Department of Medical and Health Sciences, Division of Community Medicine, National Centre for Work and Rehabilitation, Linköping University, Linköping, Sweden. ${ }^{4}$ Centre for Public Health Sciences, County Council of Östergötland, Linköping, Sweden. ${ }^{5}$ Department of Neurobiology, Health Care Sciences and Society, Division of Physiotherapy, Karolinska Institutet, Stockholm, Sweden.}

\section{Authors' contributions}

MEL, the first author, led the development of this article, oversaw data collection, worked with the study statistician to interpret findings, and organized the drafts and final version of this article. DSE, PN, KE, AS \& PB were materially involved in development of this article's first, second, and final draft and interpretation of data. Have final approval rights to the submitted version of the article. LW, was as the leading statistician at the department and had the major responsibility for statistical analyses and was materially involved in development of this article's first, second, and final draft and interpretation of data. Have final approval rights to the submitted version of the article. All authors have read and approved the final manuscript.

\section{Competing interests}

The authors declare that they have no competing interests.

Received: 25 May 2009

Accepted: 25 January 2010 Published: 25 January 2010
References

1. World Health Organisation: The World Health Report 2002: Reducing risks, promoting healthy life. WHO Geneva 2002.

2. World Health Organisation: Global strategy on diet, physical activity and health. WHO Geneva 2004.

3. James DV, Johnston LH, Crone D, Sidford AH, Gidlow C, Morris C, Foster C Factors associated with physical activity referral uptake and participation. J Sports Sci 2008, 26(2):217-224.

4. Kallings LV, Leijon M, Hellenius ML, Stahle A: Physical activity on prescription in primary health care: a follow-up of physical activity level and quality of life. Scand J Med Sci Sports 2008, 18:154-161.

5. Leijon M, Bendtsen P, Nilsen P, Festin K, Stahle A: Does a physical activity referral scheme improve the physical activity among routine primary health care patients?. Scand J Med Sci Sports 2009, 19:627-636.

6. Leijon ME, Bendtsen P, Nilsen P, Ekberg K, Stahle A: Physical activity referrals in Swedish primary health care - prescriber and patient characteristics, reasons for prescriptions, and prescribed activities. BMC Health Serv Res 2008, 8(1):201.

7. Morgan O: Approaches to increase physical activity: reviewing the evidence for exercise-referral schemes. Public Health 2005, 119(5):361-370.

8. Sorensen JB, Skovgaard T, Puggaard L: Exercise on prescription in general practice: a systematic review. Scand J Prim Health Care 2006, 24(2):69-74.

9. van Sluijs EM, van Poppel MN, Stalman WA, van Mechelen W: Feasibility and acceptability of a physical activity promotion programme in general practice. Fam Pract 2004, 21(4):429-436.

10. Aittasalo M: Physical activity counselling in primary health care. Scand J Med Sci Sports 2008, 18(3):261-262.

11. Gidlow $C$, Johnston $L H$, Crone D, James DV: Attendance of exercise referral schemes in the UK: a systematic review. Health Education Journal 2005, 64:168-186.

12. Sorensen JB, Kragstrup J, Skovgaard T, Puggaard L: Exercise on prescription: a randomized study on the effect of counseling vs counseling and supervised exercise. Scand J Med Sci Sports 2008, 18(3):288-297.

13. Wenemark M: Östgötens Hälsa 2006. Metodrapport 1 metodbeskrivning, report no 2006:10. Linköping: Folkhälsovetenskapligt Centrum, Landstinget i Östergötland 2006.

14. Leijon M: Activating People - Physical activity in the general population and referral schemes among primary health care patients in a Swedish county (Thesis). Linköping: Linköpings Universitet 2009.

15. Department of Health: At least five a week: Evidence on the impact of physical activity and its relation to health. London: Report from the Chief Medical Officer, Dep of Health, United Kingdom 2004.

16. Physical Activity Guidelines Advisory Committee: Physical Activity Guidelines Advisory Committee Report, 2008. Washington, DC: U.S: Department of Health and Human Services 2008, 1-683.

17. The Swedish National Institute of Public Health, Yrkesföreningar för fysisk aktivitet: FYSS 2008 - Fysisk aktivitet i sjukdomsprevention och sjukdomsbehandling (Physical activity in prevention and treatment of diseases) (in Swedish). Östersund: The Swedish National Institute of Public Health 2008.

18. U.S. Department of Health and Human Services: Physical Activity and Health: A report of the Surgeon General. Atlanta, GA: U.S. Department of Health and Human Services, Centers for Disease Control and Prevention, National Center for Chronic Disease Prevention and Health Promotion 1996.

19. Särndal C, Lundström S: Estimation in Surveys with Nonresponse. West Sussex, UK: John Wiley \& Sons Ltd 2005.

20. Ekberg K, Noorlind-Brage H, Dastserri M: Östgötens hälsa och miljö (in Swedish). Linköping: Folkhälsovetenskapligt Centrum Landstinget i Östergötland 2000

21. Sjöström M, Oja P, Hagströmer M, Smith B, Bauman A: Health-enhancing physical activity across European Union countries: the Eurobarometer study. J Public Health 2006, 14:291-300.

22. Albright CL, Cohen S, Gibbons L, Miller S, Marcus B, Sallis J, Imai K, Jernick J, Simons-Morton DG: Incorporating physical activity advice into primary care: physician-delivered advice within the activity counseling trial. Am J Prev Med 2000, 18(3):225-234.

23. Johansson K, Bendtsen P, Akerlind I: Advice to patients in Swedish primary care regarding alcohol and other lifestyle habits: how patients report the actions of GPs in relation to their own expectations and satisfaction with the consultation. Eur J Public Health 2005, 15(6):615-620. 
24. Rose G: Sick individuals and sick populations. Int J Epidemiol 2001, 30(3):427-432.

25. Task force on community Preventive services: Recommendations to increase physical activity in communities. Am J Prev Med 2002, 22(4):67-72.

26. Aittasalo M, Miilunpalo S: Offering physical activity counselling in occupational health care - does it reach the target group?. Occup Med 2006, 56(1):55-58.

27. Kamper-Jorgensen F, Arber S, Berkman L, Mackenbach J, Rosenstock L, Teperi J: International panel evaluation of Swedish public health research. Stockholm: Swedish Council for Working Life and Social Research. Swedish National Institute of Public HealthKamper-Jorgensen F 2004.

28. Estabrooks PA, Glasgow RE: Translating effective clinic-based physical activity interventions into practice. Am J Prev Med 2006, 31(4):S45-56.

29. Whitlock EP, Orleans $C T$, Pender $N$, Allan J: Evaluating primary care behavioral counseling interventions: an evidence-based approach. Am J Prev Med 2002, 22(4):267-284

30. The National Board of Health and Welfare: Hälso- och sjukvård lägesrapport 2003 (Health Care Status Report 2003)(in Swedish). Stockholm: Socialstyrelsen 2004

\section{Pre-publication history}

The pre-publication history for this paper can be accessed here:http://www. biomedcentral.com/1471-2458/10/34/prepub

\section{doi:10.1186/1471-2458-10-34}

Cite this article as: Leijon et al: Is there a demand for physical activity interventions provided by the health care sector? Findings from a population survey. BMC Public Health 2010 10:34.

\section{Submit your next manuscript to BioMed Central and take full advantage of:}

- Convenient online submission

- Thorough peer review

- No space constraints or color figure charges

- Immediate publication on acceptance

- Inclusion in PubMed, CAS, Scopus and Google Scholar

- Research which is freely available for redistribution

Submit your manuscript at www.biomedcentral.com/submit 